\title{
Spatiotemporal Rainfall Dynamics in Kosi Basin Using Wavelet Analysis
}

\author{
Aadil Towheed \\ Department of Civil Engineering \\ National Institute of Technology Patna \\ Patna, India \\ aadil.ce17@nitp.ac.in
}

\author{
Thendiyath Roshni \\ Department of Civil Engineering \\ National Institute of Technology Patna \\ Patna, India \\ roshni@nitp.ac.in
}

\begin{abstract}
Spatial and temporal analysis of rainfall data were carried out along with wavelet analysis for seven rain gauge sites of Kosi basin, India during the time period from 1985 to 2017 . Wavelet spectrum analysis and wavelet coherence analysis were performed to fully characterize the time-frequency rainfall variability of the rain gauge data in these areas. For all the selected gauge stations during the study period, the peak value of the wavelet power spectrum was identified for the 8-16 month band. The results of wavelet spectrum analysis reveal a good correlation of rainfall data in the rain gauge sites lying in the southwest of the Kosi basin. The spectrum analysis also differentiates the wet and dry periods and it was observed that in the majority of the selected sites, a dry period occurred from the year 2005 onwards. This was again confirmed with breakpoint analysis. The wavelet coherence analysis explicit is a good correlation between the rain gauges in the study area. Overall, the variability of the rainfall parameters was more vivid with the wavelet analysis and this can be extended to other climatological parameters.
\end{abstract}

Keywords-wavelet spectrum; wavelet coherence; break point; rainfall analysis

\section{INTRODUCTION}

The extremes of precipitation and its patterns are affected by various climatic factors and the circulation patterns in the atmosphere [1-4]. Non-stationary techniques to analyze the variation of rainfall with respect to time and space were used in [5]. The climate is mathematically defined as the weather conditions for a period of 30 years in a particular region, however it is not defined for a specific duration. The weather is defined on daily basis and is a non-linear dynamic system of the atmosphere whereas climate is considered to be the average form of weather [6]. There is a huge impact of the rainfall variation to the agricultural output in India which thereby adversely affects food security [7], Gross Domestic Product (GDP), and inflation [8]. Authors in [9] analyzed the temporal variation of precipitation in Shaheed Benazir Abad district by using the linear regression method. Rainfall events may cause the intensification of frequent extreme events which make the area more prone to floods and droughts [10]. Precipitation plays an essential role in hydro-climatic studies and daily life activities prominently in developing countries $[11,12]$. Authors in [13] focused on models to assess rainfall distribution in
Kelantan, Malaysia. Authors in [14] focused on drought frequency and its intensity in the past decades over Asia and Africa. Higher changes in precipitation events may cause increase in the span of drought periods [15]. The pattern and trend of long term precipitation extreme events are essential in the Kosin basin area which is highly prone to hazardous floods [16]. The economy and the development are dependent on the availability of water resources in the area [16].

Wavelet Transforms (WTs) of the hydro-meteorological parameters have recently drawn the attention of water resource experts. They are commonly used in data analysis and modeling [17] of hydrological and meteorological parameters. For the modeling of hydrological processes, advanced Artificial Intelligence (AI) techniques can act as robust tools [18]. During the past decades, it was observed that different AI-based models have been applied for time series analysis of rainfall data [19]. Authors in [20] used Continuous Wavelet Transform (CWT) and the multiscale entropy concept for the time series analysis of monthly rainfall data. As similar patterns are involved in the rainfall data series and due to the high potential of WT in multi-scale analysis of signals, the concept of wavelet analysis in the hydro-meteorological field can be used for better data pre-processing [21]. The variables are well identified with the help of correlation analysis and wavelet coherence [22].

In this study, WT was used as it steadily maintains the timefrequency localization in signal analysis. It also alters the $1 \mathrm{D}$ time series data into a 2D time frequency image [23]. WT analysis is also applied to signals to get detail information, which cannot be readily read from the raw signal. The objectives of the current study are: (i) to investigate the rainfall data periodically and temporally over Kosi basin synoptically and (ii) to conduct wavelet coherence analysis between the rain gauge stations of Kosi basin in order to check the correlation between the rainfall data of the different rain gauge sites for the selected time period.

\section{METHODOLOGY}

\section{A. Wavelet Analysis}

This section discusses in detail the analysis of the wavelet power spectrum.

1) Wavelet Transform 
The time series data can be analyzed at several frequencies using the WT [24]. Assuming a time series data set, $x_{n}$, where $n$ varies from 0 to $N-1$, a wavelet function $\psi_{o}(\eta)$ being the function of time as parameter $(\eta)$. The Morlet wavelet involves an exponential wave which is modulated by a Gaussian envelope as:

$$
\psi_{o}(\eta)=\pi^{-1 / 4} e^{i \omega_{o} \eta} e^{-\eta^{2} / 2}
$$

where $\omega_{o}$ is non-dimensional frequency whereas its value is taken as 6 in the present work [25]. To be allowable as a basic wavelet, function (1) implies zero mean and is localized in both time and frequency spaces.

For a discrete sequence $x_{n}$, which is separated by a constant interval of time $\delta t$, the CWT is defined for $x_{n}$ as the convolution with a translated and scaled form of $\psi_{o}(\eta)$. It is the product of the wavelet function with the original time series and is written as:

$$
W_{n}(s)=\sum_{n^{\prime}=0}^{N-1} x_{n^{\prime}} \psi^{*}\left[\frac{\left(n^{\prime}-n\right) \delta t}{s}\right]
$$

where $s$ indicates the wavelet scale which is translating along the localized time index $n,(*)$ indicates the complex conjugate, and $N$ is the number of points in time series data. Using (2) for time series analysis, this basic wavelet function is transformed to a new wavelet in time. The scaled wavelets $s$ in (3) is used to change the scale $[22,25,26]$ :

$$
\psi\left[\frac{\left(n^{\prime}-n\right) \delta t}{s}\right]=\left(\frac{\delta t}{s}\right)^{1 / 2} \psi_{o}\left[\frac{\left(n^{\prime}-n\right) \delta t}{s}\right]
$$

\section{2) Wavelet Power Spectrum}

Since wavelet function $\psi_{o}(\eta)$ and wavelet transform $W_{n}(s)$ are complex, the WT is divided into a real and an imaginary part. The wavelet power spectrum is now defined as $\left[W_{n}(s)\right]^{2}$ (detailed description is given in [25]). The parameters used for the analysis of rainfall data are $\delta t=1$ month, $\mathrm{S}_{0}=2 \delta t$, $\delta j=0.25$, (shows 4 sub-octaves per octave), $j_{l}=7 / \delta j$ ( 7 powers of two with $\delta j$ sub-octaves).

\section{3) Global Wavelet Power Spectrum}

The global wavelet power spectrum is the square of the WT. The time-averaged wavelet spectrum over a period is given by:

$$
W_{n}^{2}(s)=\frac{1}{N} \sum_{n=0}^{N}\left|W_{n}(s)\right|^{2}
$$

\section{4) Scale-Average Time Series}

The time series of scale average is the average variance in a certain band. In the present work the selected band is the 8-16 month band after the analysis.

\section{B. Wavelet Coherence Analysis (WCA)}

WCA is applied generally in catchment studies, space and time analysis, and for model validation. The WCA examines the correlation and phase lag between two series of time data as a function of both time and frequency [27]. Authors in [28] defined wavelet coherence for $X(n)$ and $Y(n)$ as two time series.

$$
R_{n}^{2}(s)=\frac{\mid S\left(\left.s^{-1} W_{n}^{X Y}(s)\right|^{2}\right.}{S\left(s^{-1}\left|W_{n}^{X}(s)\right|^{2}\right) \cdot S\left(s^{-1}\left|W_{n}^{Y}(s)\right|^{2}\right)}
$$

where $S$ is a smoothing operator and $W_{n}^{x}(s)$ and $W_{n}^{y}(s)$ are wavelet transforms of $X(n)$ and $Y(n)$ time series. $W_{n}^{X Y}(s)=W_{n}^{X}(s) W_{n}^{Y^{*}}(s)$ is the cross-wavelet transform, where $\left(^{*}\right)$ represents the complex conjugate and $W_{n}^{x}(s)$ is the cross wavelet power [17]. The statistical significance level of WCA is estimated with Monte Carlo methods. The value of $R^{2}$ ranges from 0 to 1 , and is conceptualized as a localized correlation coefficient with time and frequency space. WCA for the signal comparison is carried out using the MATLAB functions provided by [28].

\section{STUDY AREA AND AVAILABLE DATA}

The Kosi river enters Bihar near Bhimnagar after draining a large area in Nepal. The drainage area $\left(\sim 52,731 \mathrm{~km}^{2}\right)$ includes parts of Tibet, Nepal, and India [29]. The Kosi river is one of the most flood-prone rivers in India and is located in north Bihar. The study area extends between $25^{0} 19^{\prime} 18^{\prime \prime} \mathrm{N}$ $26^{\circ} 43^{\prime} 30^{\prime \prime} \mathrm{N}$ latitude and $87^{\circ} 4^{\prime} 35^{\prime \prime} \mathrm{E}-87^{\circ} 12^{\prime} 32^{\prime \prime} \mathrm{E}$ longitude. Some major tributaries of the Kosi river are Kamlabalan, Bagmati, and Bhutibalan. The Shuttle Radar Topography Mission (SRTM) based Digital Elevation Model (DEM) was used for the determination of elevation (maximum $109 \mathrm{~m}$ ) of the study area. There are 10 districts within the Kosi river basin while the degree of slope varies from 0 to $35^{\circ}$. The spatial variation of rainfall and subsequently its effect in the soil erosion in the Kosi river was well studied in [30]. The main reason to choose this study area is that it is very vulnerable to the adverse effects of floods.

The teleconnections of the different regions within the study area are quite significant, as India has different climatic conditions and rainfall patterns [31]. Authors in [32] utilized the precipitation data to look into the effects of teleconnections on extreme precipitation for a period of 113 years. For the current study, the daily rainfall data were collected from India Meteorological Department (IMD), Pune for a duration of 33 years (1985 - 2017) for 6 raingauge stations (Kursela, Galgalia, Murliganj, Nirmali, Bhimnagar, and Bahadurganj) and 19852015 for Birpur station [30]. Concentration of rainfall occurs high in the monsoon season (from May to October) within the study area. The maximum average annual rainfall is $2,711.95 \mathrm{~mm}$ obtained in Galgalia, and the least is $1,249.13 \mathrm{~mm}$ in Bhimnagar [30].

\section{RESULTS AND DISCUSSION}

\section{A. Wavelet Transform}

The WT is computed with the help of the MATLAB script developed in [25]. In Kosi basin, the CWT is performed for the monthly data of 7 gauging stations. For the computation of (3), $\delta t$ and $s$ used were 1 month and 2 months (as $s=2 \delta t$ ), 7 powers of 2 with 4 sub-octaves per octave and 'Morlet' as mother wavelet were used. The time series plots of monthly rainfall for the 7 gauging stations are shown in Figures 1(a)-7(a) for 395 
months (1985-2017), except for the Birpur station (1985-2015). Figures 1(b)-7(b) show the power (squared absolute value) of the WT for the monthly rainfall data. This provides information on relative power at a certain scale and it displays the actual oscillations of the individual wavelets. Figures 1(c)-7(c) show the global wavelet spectrum and Figures 1(d)-7(d) show the variance of the power for a particular band of interest for the respective stations.

Figure 1(b) is evaluated for different frequency bands varying from 2 to 256 months for Bahadurganj data. The figures with color fill show the variation of rainfall in which the ranges of power are from weak (deep blue shades) to strong (dark red shades). Thus, the time series differences were mapped to wavelet region and to various scales. It is worth noting that the power is more for the 8-16 month band throughout the selected period and it is confirmed with the peak in the global wavelet power spectrum (Figure 1(c)). The scale average time series of average variance in the 8-16 month band is shown in Figure 1(d). The variance plot shows distinct dry and wet periods. The power decreases substantially during a dry year and maximum power means a wet year [34, 35]. In Bahadurganj, wet periods are observed more than dry periods throughout the studied duration. Similarly for Figures 2(b)$7(\mathrm{~b})$, it is clearly visible that the power is more for the 8-16 month band throughout the selected time duration for all the selected sites and it is also confirmed with the peak in the global wavelet power spectrum (Figures 1(c)-7(c)). Hence, the scale average time series of average variance is plotted for the 8-16 month band only for the selected time period (Figures 1(d)-7(d)). In Bhimnagar, a significant wet period is observed during the 200-250 week period. However, wet periods are observed up to 240 months (from year 1985), with a few breakdowns during the months 60-100 in Birpur.
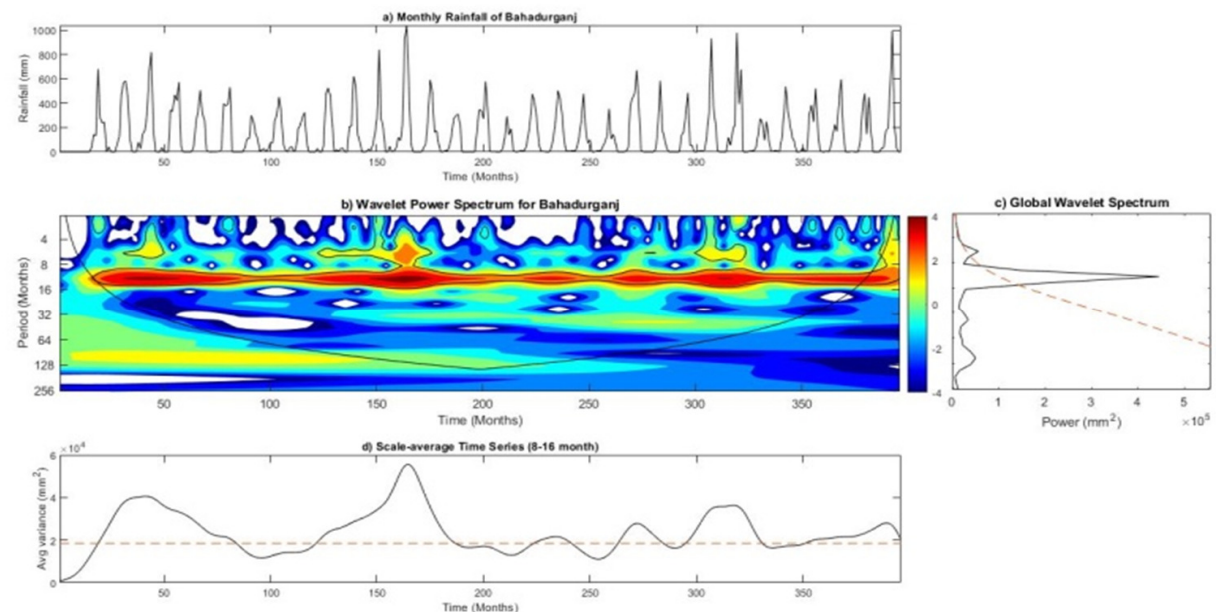

Fig. 1. Bahadurganj station: (a) Time series plot of monthly rainfall. (b) Analysis of the wavelet power spectrum for monthly rainfall data with Morlet as mother-wavelet. (c) The global wavelet spectrum (black continuous line) and significance level 5\% (broken red line). (d) $8-16$ month band scale-average time series of wavelet power (black continuous line). The broken red line is the $95 \%$ confidence level.
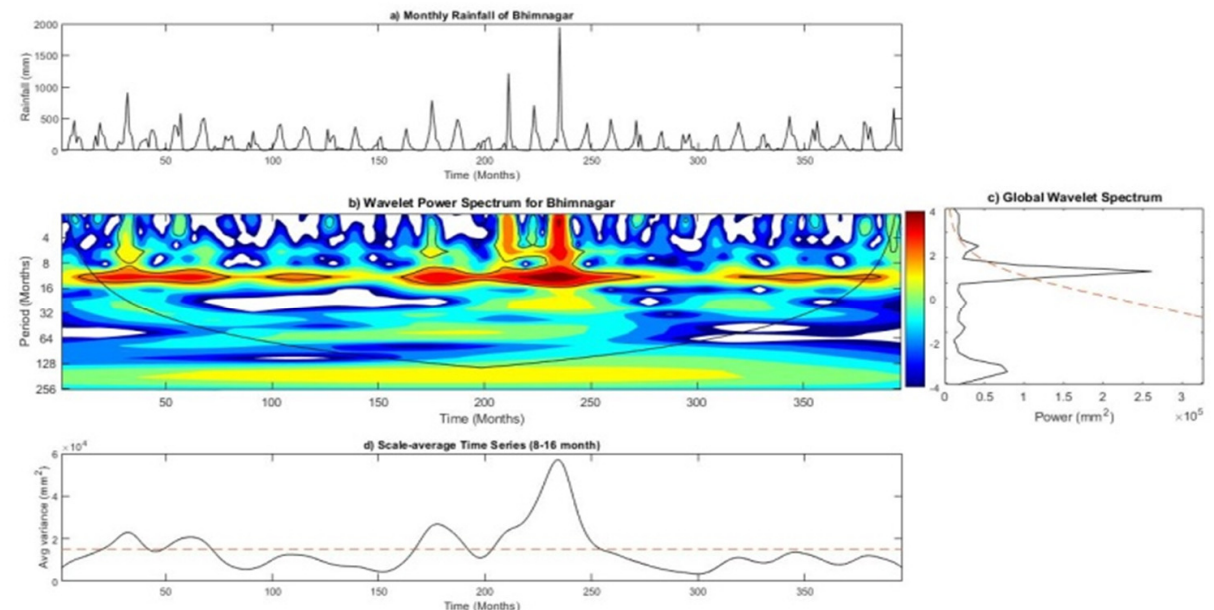

Fig. 2. Bhimnagar station: (a) Time series plot of monthly rainfall. (b) Analysis of the wavelet power spectrum for monthly rainfall data with Morlet as mother-wavelet. (c) The global wavelet spectrum (black continuous line) and significance level 5\% (broken red line). (d) 8-16 month band scale-average time series of wavelet power (black continuous line). The broken red line is the $95 \%$ confidence level. 

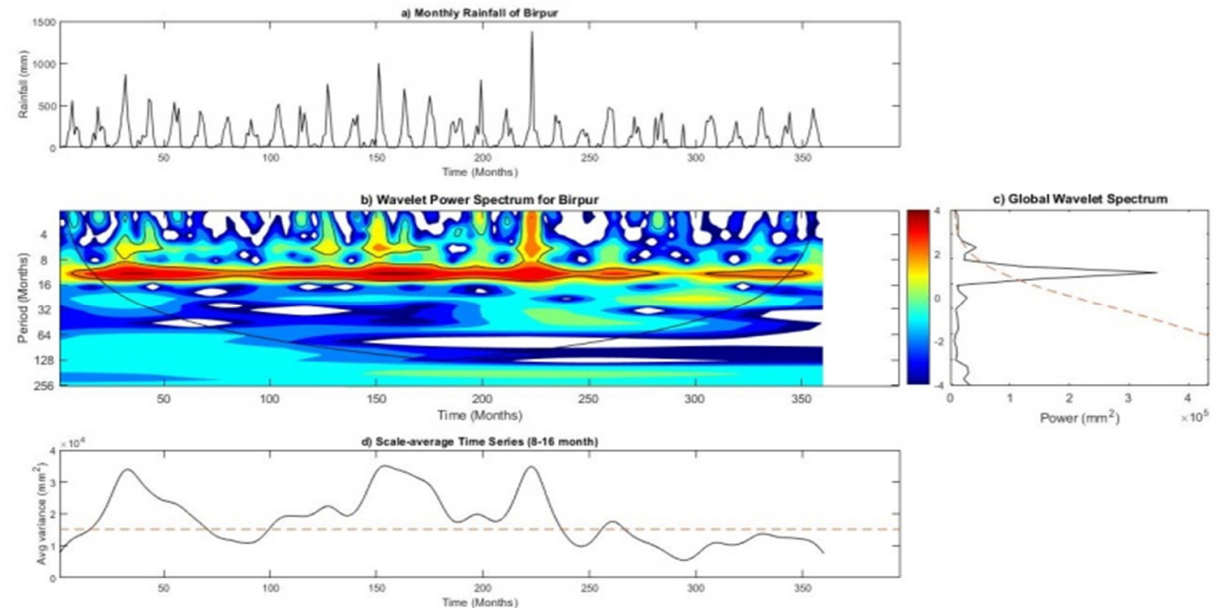

Fig. 3. Birpur station: (a) Time series plot of monthly rainfall. (b) Analysis of the wavelet power spectrum for monthly rainfall data. (c) The global wavelet spectrum and significance level 5\%. (d) 8-16 month band scale-average time series of wavelet power. The broken red line is the $95 \%$ confidence level.
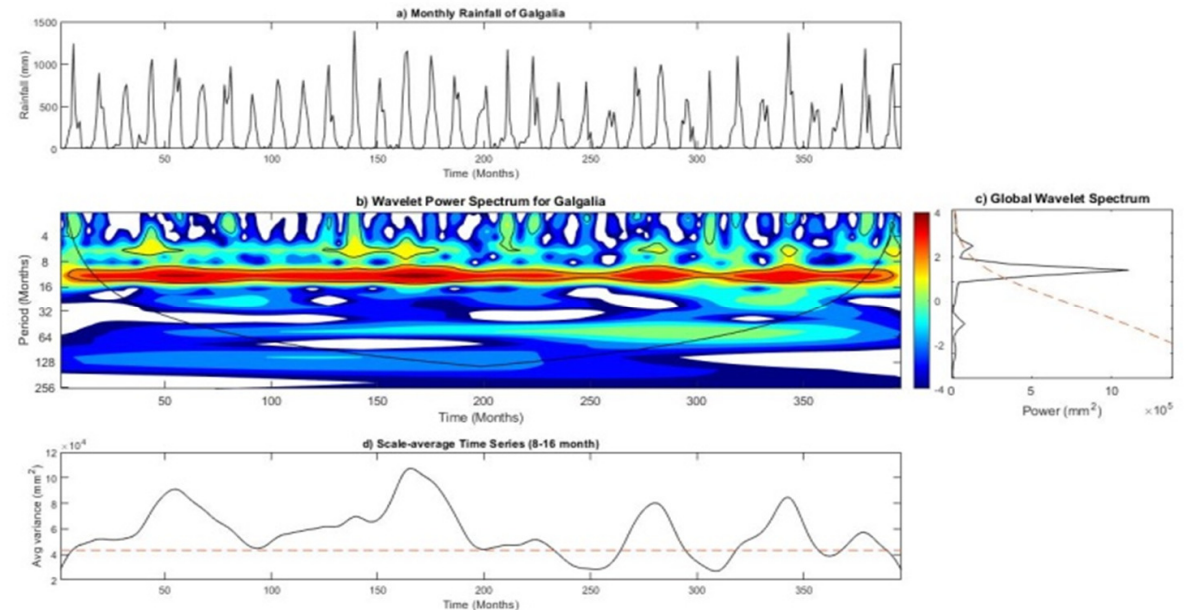

Fig. 4. Galgalia station: (a) Time series plot of monthly rainfall. (b) Analysis of the wavelet power spectrum for monthly rainfall data. (c) The global wavelet spectrum and significance level 5\%. (d) 8-16 month band scale-average time series of wavelet power. The broken red line is the $95 \%$ confidence level.
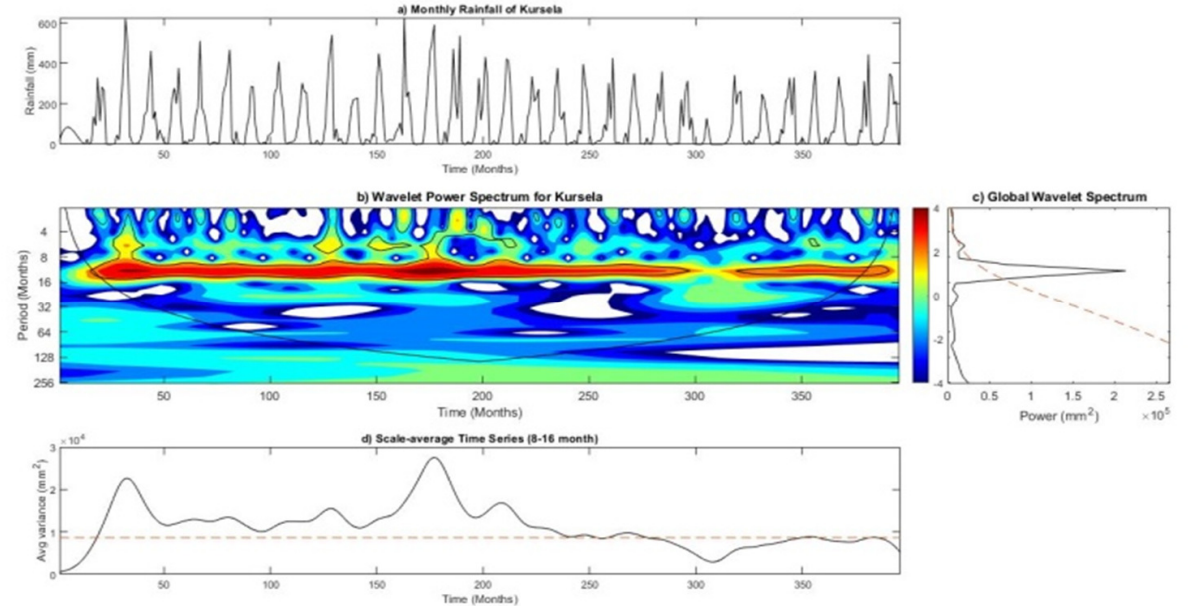

Fig. 5. Kursela station: (a) Time series plot of monthly rainfall. (b) Analysis of the wavelet power spectrum for monthly rainfall data. (c) The global wavelet spectrum and significance level 5\%. (d) 8-16 month band scale-average time series of wavelet power. The broken red line is the $95 \%$ confidence level. 

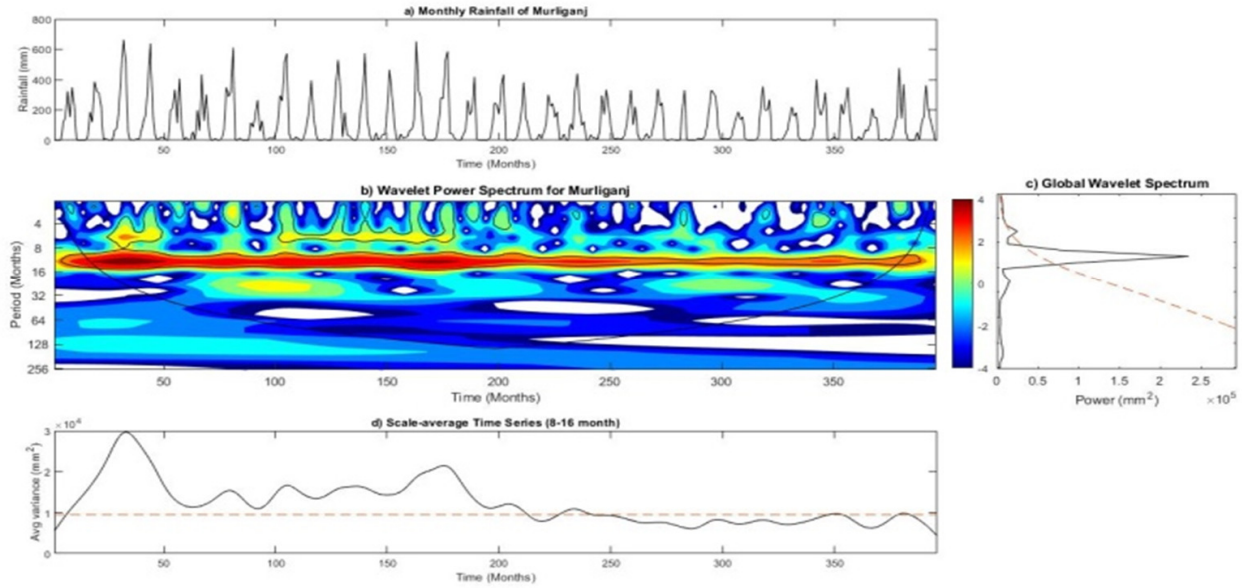

Fig. 6. Murliganj station: (a) Time series plot of monthly rainfall. (b) Analysis of the wavelet power spectrum for monthly rainfall data. (c) The global wavelet spectrum and significance level 5\%. (d) 8-16 month band scale-average time series of wavelet power. The broken red line is the $95 \%$ confidence level.
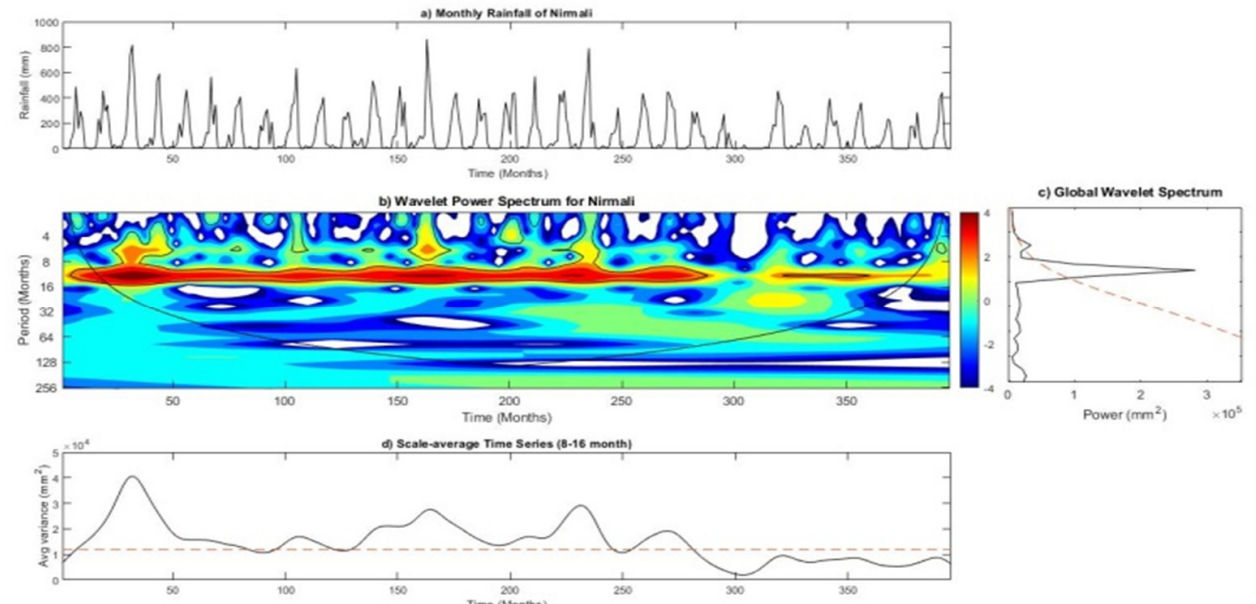

Fig. 7. Nirmali station: (a) Time series plot of monthly rainfall. (b) Analysis of the wavelet power spectrum for monthly rainfall data. (c) The global wavelet spectrum and significance level 5\%. (d) 8-16 month band scale-average time series of wavelet power. The broken red line is the $95 \%$ confidence level.

In Galgalia, it is interesting to note that in the 8-16 band, the average power variance indicates a wet period throughout the time period except a few breakdowns during 240-260 and 300-320 months (Figure 4(d)). In Kursela (Figure 5(d)), a wet period is observed until 280 months and after, until the end of the studied duration, a continuous dry period is observed. Similarly in Murliganj (Figure 6(d)) and in Nirmali (Figure 7(d)) a continuous dry period is observed after 240 and 280 months. It is concluded from the wavelet power spectrum analysis for all the selected gauging stations for the selected time period shows that maximum power spectrum is observed in the 8-16 band. A similar observation in the variance also seen towards the southwest of Kosi basin (Kursela, Murliganj, Birpur and Nirmali, see Figure 1 in [30]).

\section{B. Wavelet Coherence Analysis}

Figure 8(a-c) shows the WCA between the Galgalia and Murliganj, Galgalia and Birpur, Kursela and Bhimnagar stations. It is clearly visible from the Figure that there is a good correlation between all the selected sites during the studied time period. Even though short breakdowns are visible for shorter time periods, the majority shows a very good coherence between the signals. This study is also proving the findings of [36] that WCA could be a useful tool to detect the relationship between rainfall in different sites of the same basin.

From the above results, it is clear that there is a good correlation between the rainfall of the selected gauging stations for the selected time period which is averaged and shown in Figure 9. It is found that the rainfall months are observed from the month of May to October throughout the studied duration with peaks during 1985-1990, 1995-2000, and 2000-2005. Maximum monthly rainfall reaches $700 \mathrm{~mm}$ during the selected time duration. After 2005, a considerable decrease in the rainfall is observed. This is also in accordance with the average variance results of the wavelet spectrum analysis. This finding can be strengthened by the breakpoint analysis for the basin shown in Figure 10. It is found that after 237 months, there is a reduction in the mean rainfall from $147.7 \mathrm{~mm}$ to $116.3 \mathrm{~mm}$. 
(a)

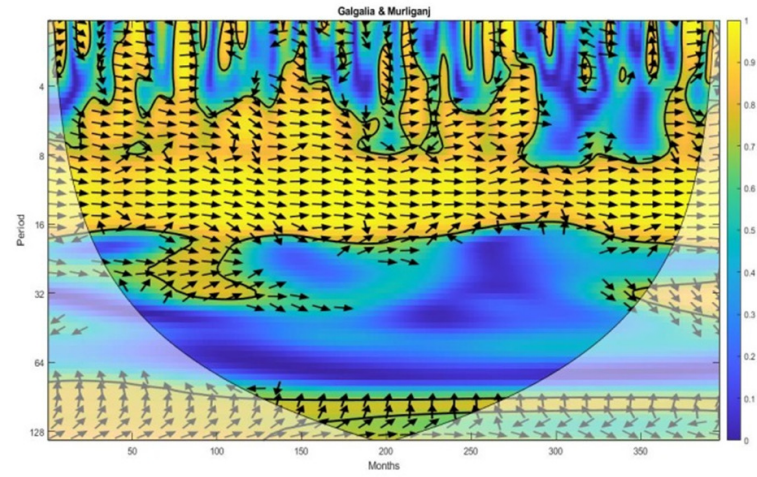

(b)

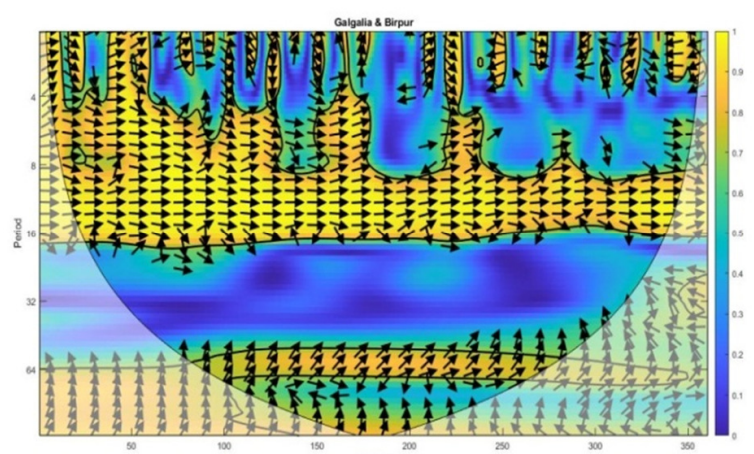

(c)

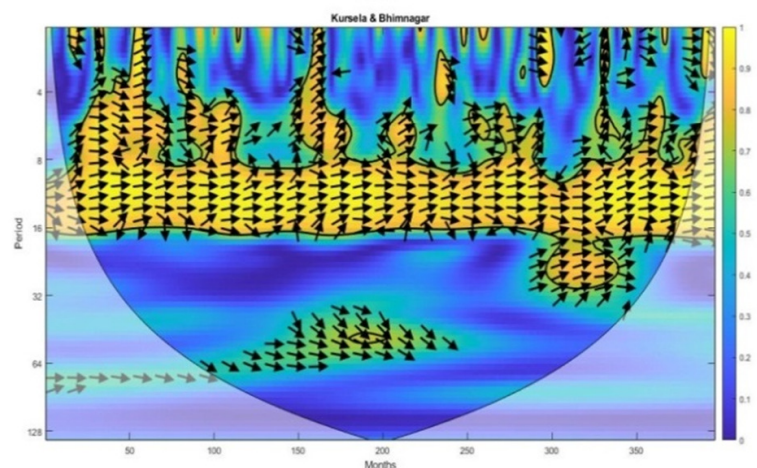

Fig. 8. Wavelet coherence analysis between: (a) Galgalia and Murliganj, (b) Galgalia and Birpur, and (c) Kursela and Bhimnagar.

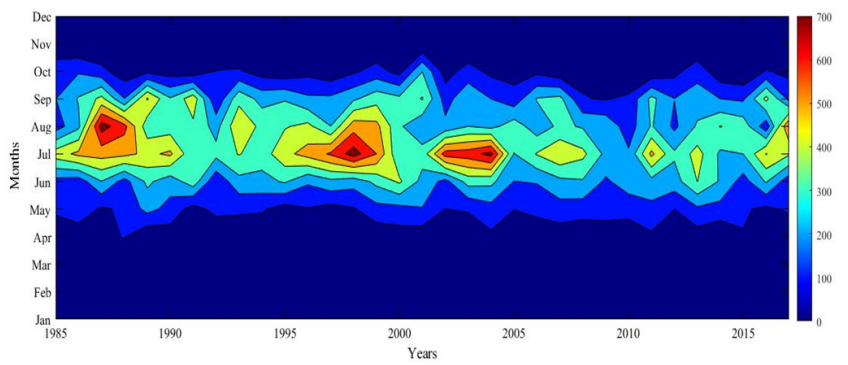

Fig. 9. Monthly average rainfall over the entire Kosi basin during the 1985-2017 period.

\section{CONCLUSION}

To study the variability of the rainfall in the Kosi basin, wavelet spectrum analysis and wavelet coherence analysis were performed. The wavelet spectrum analysis for the monthly time series data for all the selected 7 rain gauge stations during the
1985-2017 period show large power concentration in the 8-16 month band. This reveals an annual periodicity of events and is also confirmed by the peak in the global wavelet spectrum.

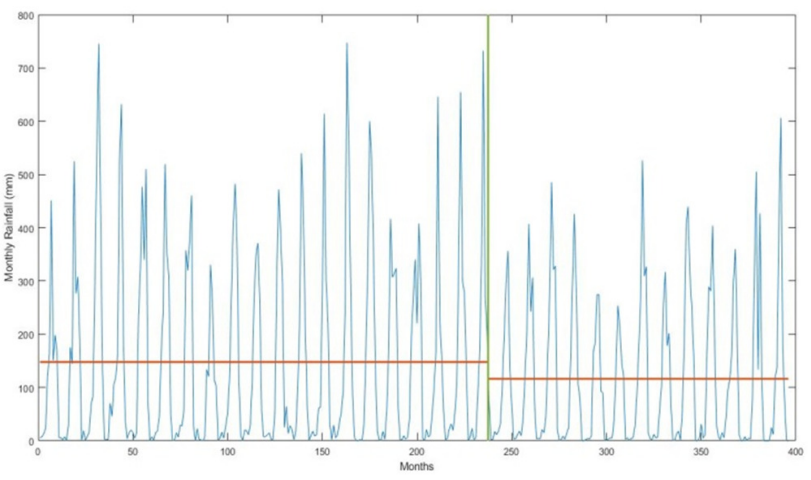

Fig. 10. Breakpoint analysis of the monthly average rainfall data of the Kosi basin during the $1985-2017$ period.

Scale averaged time series of the selected 8-16 band reveals that the regions in the southwest of the Kosi basin show similar patterns of dry and wet periods during the studied time duration. Wavelet coherence analysis of the rainfall data reveals a good correlation between the selected stations. The average rainfall data also confirm the considerable reduction in the rainfall towards the beginning of the year 2005. Break point analyses were also in accordance with the results of the average rainfall data and found a breakdown of average rainfall from $147.7 \mathrm{~mm}$ to $116.3 \mathrm{~mm}$ for the selected time duration.

\section{REFERENCES}

[1] C. P. Khedun, A. K. Mishra, V. P. Singh, and J. R. Giardino, "A copulabased precipitation forecasting model: Investigating the interdecadal modulation of ENSO's impacts on monthly precipitation," Water Resources Research, vol. 50, no. 1, pp. 580-600, 2014, https://doi.org/ 10.1002/2013WR013763.

[2] D. Himayoun and T. Roshni, "Spatio-temporal variation of drought characteristics, water resource availability and the relation of drought with large scale climate indices: A case study of Jhelum basin, India," Quaternary International, vol. 525, pp. 140-150, Aug. 2019, https://doi.org/10.1016/j.quaint.2019.07.018.

[3] C. D. Ahrens and R. Henson, Meteorology Today, 11th ed. Toronto, Canada: Cengage Learning, 2015.

[4] C. Sireesha, T. Roshni, and M. K. Jha, "Insight into the precipitation behavior of gridded precipitation data in the Sina basin," Environmental Monitoring and Assessment, vol. 192, no. 11, Oct. 2020, Art. no. 729, https://doi.org/10.1007/s10661-020-08687-3.

[5] M. H. Elsanabary, T. Y. Gan, and D. Mwale, "Application of wavelet empirical orthogonal function analysis to investigate the nonstationary character of Ethiopian rainfall and its teleconnection to nonstationary global sea surface temperature variations for 1900-1998," International Journal of Climatology, vol. 34, no. 6, pp. 1798-1813, 2014, https://doi.org/10.1002/joc.3802.

[6] M. Suman and R. Maity, "Hybrid Wavelet-ARX approach for modeling association between rainfall and meteorological forcings at river basin scale," Journal of Hydrology, vol. 577, Oct. 2019, Art. no. 123918, https://doi.org/10.1016/j.jhydrol.2019.123918.

[7] S. Kumar, T. Roshni, E. Kahya, and M. A. Ghorbani, "Climate change projections of rainfall and its impact on the cropland suitability for rice and wheat crops in the Sone river command, Bihar," Theoretical and Applied Climatology, vol. 142, no. 1, pp. 433-451, Oct. 2020, https://doi.org/10.1007/s00704-020-03319-9. 
[8] S. Gadgil and S. Gadgil, "The Indian Monsoon, GDP and Agriculture," Economic and Political Weekly, vol. 41, no. 47, pp. 4887-4895, 2006.

[9] S. R. Samo, N. Bhatti, A. Saand, M. A. Keerio, and D. K. Bangwar, "Temporal Analysis of Temperature and Precipitation Trends in Shaheed Benazir Abad Sindh, Pakistan," Engineering, Technology \& Applied Science Research, vol. 7, no. 6, pp. 2171-2176, Dec. 2017, https://doi.org/10.48084/etasr.1388.

[10] A. J. McMichael et al., Eds., Climate change and human health: risks and responses. Geneva, Switzerland: World Health Organization, 2003.

[11] K. Ahmed, S. Shahid, and S. B. Harun, "Spatial interpolation of climatic variables in a predominantly arid region with complex topography," Environment Systems and Decisions, vol. 34, no. 4, pp. 555-563, Dec. 2014, https://doi.org/10.1007/s10669-014-9519-0.

[12] W. Wang, S. Wang, X. Ma, and J. Gong, "Recent advances in catalytic hydrogenation of carbon dioxide," Chemical Society Reviews, vol. 40, no. 7, pp. 3703-3727, Jun. 2011, https://doi.org/10.1039/C1CS15008A.

[13] A. H. Syafrina, A. Norzaida, and O. N. Shazwani, "Stochastic Modeling of Rainfall Series in Kelantan Using an Advanced Weather Generator," Engineering, Technology \& Applied Science Research, vol. 8, no. 1, pp. 2537-2541, Feb. 2018, https://doi.org/10.48084/etasr.1709.

[14] K. L. Ebi, R. S. Kovats, and B. Menne, "An Approach for Assessing Human Health Vulnerability and Public Health Interventions to Adapt to Climate Change," Environmental Health Perspectives, vol. 114, no. 12, pp. 1930-1934, Dec. 2006, https://doi.org/10.1289/ehp.8430.

[15] P. Högy, C. Poll, S. Marhan, E. Kandeler, and A. Fangmeier, "Impacts of temperature increase and change in precipitation pattern on crop yield and yield quality of barley," Food Chemistry, vol. 136, no. 3, pp. 14701477, Feb. 2013, https://doi.org/10.1016/j.foodchem.2012.09.056.

[16] P. K. Srivastava et al., "Long-Term Trend Analysis of Precipitation and Extreme Events over Kosi River Basin in India," Water, vol. 13, no. 12 , Jan. 2021, Art. no. 1695, https://doi.org/10.3390/w13121695.

[17] T. Roshni, M. K. Jha, R. C. Deo, and A. Vandana, "Development and Evaluation of Hybrid Artificial Neural Network Architectures for Modeling Spatio-Temporal Groundwater Fluctuations in a Complex Aquifer System," Water Resources Management, vol. 33, no. 7, pp. 2381-2397, May 2019, https://doi.org/10.1007/s11269-019-02253-4.

[18] B. S. N. Reddy, S. K. Pramada, and T. Roshni, "Monthly surface runoff prediction using artificial intelligence: A study from a tropical climate river basin," Journal of Earth System Science, vol. 130, no. 1, Feb. 2021, Art. no. 35 (2021), https://doi.org/10.1007/s12040-020-01508-8.

[19] S. J. Burian, S. J. Nix, R. E. Pitt, and S. R. Durrans, "Urban Wastewater Management in the United States: Past, Present, and Future," Journal of Urban Technology, vol. 7, no. 3, pp. 33-62, Dec. 2000, https://doi.org/ $10.1080 / 713684134$.

[20] K. Roushangar, F. Alizadeh, and J. Adamowski, "Exploring the effects of climatic variables on monthly precipitation variation using a continuous wavelet-based multiscale entropy approach," Environmental Research, vol. 165, pp. 176-192, Aug. 2018, https://doi.org/ 10.1016/j.envres.2018.04.017.

[21] V. Nourani and N. Farboudfam, "Rainfall time series disaggregation in mountainous regions using hybrid wavelet-artificial intelligence methods," Environmental Research, vol. 168, pp. 306-318, Jan. 2019, https://doi.org/10.1016/j.envres.2018.10.012.

[22] S. Sithara, S. K. Pramada, and S. G. Thampi, "Sea level prediction using climatic variables: a comparative study of SVM and hybrid wavelet SVM approaches," Acta Geophysica, vol. 68, no. 6, pp. 1779-1790, Dec. 2020, https://doi.org/10.1007/s1 1600-020-00484-3.

[23] C. A. G. Santos, I. C. Guerra-Gomes, B. M. Gois, R. F. Peixoto, T. S. L. Keesen, and R. M. da Silva, "Correlation of dengue incidence and rainfall occurrence using wavelet transform for João Pessoa city," Science of The Total Environment, vol. 647, pp. 794-805, Jan. 2019, https://doi.org/10.1016/j.scitotenv.2018.08.019.

[24] I. Daubechies, "The wavelet transform, time-frequency localization and signal analysis," IEEE Transactions on Information Theory, vol. 36, no. 5, pp. 961-1005, Sep. 1990, https://doi.org/10.1109/18.57199.

[25] C. Torrence and G. P. Compo, "A Practical Guide to Wavelet Analysis.," Bulletin of the American Meteorological Society, vol. 79, pp. 61-78, Jan.
1998, https://doi.org/10.1175/1520-0477(1998)079<0061:APGTWA> 2.0.CO;2.

[26] J. O. Adepitan and E. O. Falayi, "Variability changes of some climatology parameters of Nigeria using wavelet analysis," Scientific African, vol. 2, Mar. 2019, Art. no. e00017, https://doi.org/10.1016/ j.sciaf.2018.e00017.

[27] C. Chang and G. H. Glover, "Time-frequency dynamics of resting-state brain connectivity measured with fMRI," NeuroImage, vol. 50, no. 1, pp. 81-98, Mar. 2010, https://doi.org/10.1016/j.neuroimage.2009.12.011.

[28] A. Grinsted, J. C. Moore, and S. Jevrejeva, "Application of the cross wavelet transform and wavelet coherence to geophysical time series," Nonlinear Processes in Geophysics, vol. 11, no. 5/6, pp. 561-566, Nov. 2004, https://doi.org/10.5194/npg-11-561-2004.

[29] K. Mishra and R. Sinha, "Flood risk assessment in the Kosi megafan using multi-criteria decision analysis: A hydro-geomorphic approach," Geomorphology, vol. 350, Feb. 2020, Art. no. 106861, https://doi.org/ 10.1016/j.geomorph.2019.106861.

[30] A. Towheed and T. Roshni, "Linking climate change to soil loss estimation in the Kosi river basin, India," Journal of Water and Climate Change, Mar. 2021, Art. no. jwc2021259, https://doi.org/10.2166/wcc. 2021.259.

[31] M. Rathinasamy, A. Agarwal, B. Sivakumar, N. Marwan, and J. Kurths, "Wavelet analysis of precipitation extremes over India and teleconnections to climate indices," Stochastic Environmental Research and Risk Assessment, vol. 33, no. 11, pp. 2053-2069, Dec. 2019, https://doi.org/10.1007/s00477-019-01738-3.

[32] A. Agarwal, "Unraveling spatio-temporal climatic patterns via multiscale complex networks," Ph.D. dissertation, University of Potsdam, Potsdam, Germany, 2019.

[33] N. Saada, M. R. Abdullah, A. Hamaideh, and A. Abu-Romman, "Application of Stochastic Analysis, Modeling and Simulation (SAMS) to Selected Hydrologic Data in the Middle East," Engineering, Technology \& Applied Science Research, vol. 9, no. 3, pp. 4261-4264, Jun. 2019, https://doi.org/10.48084/etasr.2750.

[34] J. C. N. dos Santos, E. M. de Andrade, M. J. S. Guerreiro, P. H. A. Medeiros, H. A. de Queiroz Palácio, and J. R. de Araújo Neto, "Effect of dry spells and soil cracking on runoff generation in a semiarid micro watershed under land use change," Journal of Hydrology, vol. 541, pp. 1057-1066, Oct. 2016, https://doi.org/10.1016/j.jhydrol.2016.08.016.

[35] V. A. H. F. D. Santos et al., "Causes of reduced leaf-level photosynthesis during strong El Niño drought in a Central Amazon forest," Global Change Biology, vol. 24, no. 9, pp. 4266-4279, Sep. 2018, https://doi.org/10.1111/gcb.14293.

[36] V. Nourani and S. Mousavi, "Spatiotemporal groundwater level modeling using hybrid artificial intelligence-meshless method," Journal of Hydrology, vol. 536, pp. 10-25, May 2016, https://doi.org/ 10.1016/j.jhydrol.2016.02.030. 